\title{
HINKELBEINCHEN UND "LITTLE CHICKEN'S LEG": DEUTSCHE UND AMERIKANISCHE IDIOME ALS KOMMUNIKATIVE TEXTSORTEN-PROBLEMATIK
}

Hyeonmi zum

zehnten Jahrestage

Als Marin Luther 1522 seine Übersetzung des Neuen Testaments nach der griechischen Edition des Erasmus von Rotterdam abschloß, hatte er dabei zwar mit größtem Sprachgefühl nicht nur dem deutschen, sondern auch dem idiomatischen 'logos' des Griechischen "auf das Maul" gesehen. Aber er mußte in seinem "Sendbrief vom Dolmetschen" 1530 dennoch zugeben, daß selbst er - zusammen mit seinen beiden Assistenten Melanchthon und Aurogallus - sehr oft zwei bis vier Wochen lang nach einem einzigen idiomatisch treffenden Wort zu suchen hatte. Damit wird von einem eminenten Kronzeugen, nämlich vom Schöpfer des protestantischen 'Hausbuches' Lutherbibel und vom eigentlichen Begründer einer einheitlichen deutschen Schriftsprache, samt ihrer sprach- und literargeschichtlich wirkungsmächtigen Idiomatik, die Schwierigkeit und Problematik idiomatischer Äquivalenzen und Transferenzen zwischen den Einzelsprachen verbürgt.

Die Lutherbibel mit ihrem Lutherdeutsch war und ist zunächst Sprache als Kommunikation, und zwar Sprache als reformatorische Mitteilung, als reformatorisches Postulat eines neuen direkt-kommunikativen Verhältnisses zwischen menschlichem Individuum und Gott. Luther-Bibel und Luther-Deutsch waren und sind aber zugleich generative 'Text'-Ausformungen aus der kompositionellen UniversalitätsKategorie 'deutsche Sprache' durch einen thematisch determinierten Akt kreativer sprachlicher Autonomie des Individuums Martin Luther in den quantitativen und allen qualitativ-formalen Bereichen des Deutschen nach einheitlich-kategorialen Selektionsprinzipien, den ich hier im November 1994 als "Stil" definiert habe. ${ }^{1}$ Sie sind folglich als 'Stil'-Leistung - Sprache als Kunstwerk, das der kommunikativen Zeit-Kategorie enthoben ist. Was ich damit ansagen will, ist eine mir bewußte und vorausgesetzte Unterscheidung von Sprache als Textsorten-orientierte, zeitgebundene Kommunikation und von Sprache als zeitloses, Stil-orientiertes Sprachkunstwerk. Wobei sich gerade

1 Vgl. meinen Beitrag: "Sprache, Text und Textsorten: Zur Problematik von Texttypologie". In: Linguistica XXXV,1: Textsorten. Ljubljana 1995, S. 53-79, hier: S. 64-66. 
anhand von Luthers Auslassungen im "Sendbrief" zeigen läßt, wie integral zu dem 'bewußten Kunst-Akt' des Lutherischen 'Stils' die ebenfalls 'bewußte' und 'gewußte', mithin kognitiv-integrierte und selektiv-einsichtige Verwendung von 'stilistischen Fertigteilen', also Textsorten, als konstituierende idiomatische Matrix gehört, obwohl es sich dabei scheinbar um ein plagiatorisches Vorgehen handelt. Denn auch die heute nach meiner Definition antistilistisch determinierte, stereotyp-formelhafte EinzeltextKomponente 'Textsorte' 2 ist im historischen Kontinuum der Sprache ursprünglich als durchaus einmalige, aktiv-autonome Stil-Leistung eines Individuums entstanden, das in der Anonymität verschwunden ist und das seine Stil-Leistung der Muttersprache als Allmende zum allgemeinen Gebrauch überlassen hat. Wie dominant-virtuos sich idiomatische Textsorten sogar und gerade im zeitgenössischen Wortkunstwerk einsetzen lassen, hat Walter Kempowski in seinen familienhistorischen Prosawerken demonstriert. Das heißt, wir Heutigen - die wir nicht mehr 'naiv' am phylogenetischen 'Anfang' unserer Sprache partizipieren, es nur noch, mit Schiller, 'sentimentalisch' tun - müssen uns in der Regel damit bescheiden, möglichst gekonnt und treffend auf der geradezu unendlichen Klaviatur der vorgegebenen idiomatischen Textsorten einer Sprache kommunikativ-stilistisch zu improvisieren und dabei auf den richtigen Anschlag zu achten. Das gilt besonders, wenn wir auf der Textsorten-Klaviatur einer uns nicht angeborenen Sprache intonieren, weil wir uns dabei in eine uns fremde Tonart und Kompositionsform begeben. Nur wer zu den seltenen Meistern des 'puren Stils'3 einer Nationalsprache gehört, kann die magische Potenz seiner Sprache aktivieren und das leisten, was Luther zu Beginn des Johannes-Evangeliums, trotz aller GoethischFaustischen Umdeutungsversuche, endgültig formulierte als: "Im Anfang war das Wort, und das Wort war bei Gott, und Gott war das Wort... Alle Dinge sind durch dasselbe (= das Wort) gemacht, und ohne dasselbe ist nichts...", was Rilke knapp 2 1/2 Jahre vor seinem Tode in dem Gedicht "Magie" als Schöpfungsakt einer "unbeschreiblichen Verwandlung" der Dinge unserer Existenz durch den Stil lyrisch-orphischer Sprache begriff" und was Gottfried Benn 1941 so ausdrückte: "Ein Wort, ein Satz-: Aus Chiffren steigen/ erkanntes Leben, jäher Sinn,/ die Sonne steht, die Sphären schweigen,/ und alles ballt sich zu $i h m$ hin..."5

Daß nicht nur - und sogar - Martin Luther an den Schwierigkeiten idiomatischer Äquivalenzen bei der stilistischen Erarbeitung seines Bibel-Textes wochenlang hängenblieb und - nach eigenem Eingeständnis im "Sendbrief" - das gesuchte Idiom

2 Zu meiner Textsorten-Definition vgl. ebd., S. 68ff.

3 Vgl. dazu ebd., S. 75ff.

4 Vgl. R.M. Rilke, Die Gedichte. ${ }^{7}$ Frankfurt/Main 1995, S. 960: "Aus unbeschreiblicher Verwandlung stammen/ solche Gebilde -: Fühl! und glaub!/ Wir leidens oft: zu Asche werden Flammen;/ doch, in der Kunst: zur Flamme wird der Staub.// Hier ist Magie. In das (!) Bereich des Zaubers/ scheint das gemeine Wort hinaufgestuft.../ und ist doch wirklich wie der Ruf des Taubers,/ der nach der unsichtbaren Taube ruft." 342. 
"dennoch zuweilen nicht gefunden", ergibt sich aus einem eklatanten Beleg im uvre des international geehrten Übersetzers Ralph Manheim. Manheim publizierte 1977, zum ersten Male in englischer Sprache, die Gesamtausgabe der Grimmschen "Kinder- und Hausmärchen". Zuvor waren die Märchen lediglich in unterschiedlicher Auswahl erschienen, sicher wegen der Problematik einer idiomatisch adäquaten Übersetzung für englischsprachige Leser. Für diese beachtliche Übersetzungs-Premiere eines Textes der Weltliteratur erhielt Manheim sogleich einen Pulitzer-Preis und im Jahre 1988 den deutschen "Schlegel-Tieck-Übersetzerpreis", obwohl seine Übersetzungen gelegentlich an idiomatischen Verzerrungen kranken, wie im folgenden Beispiel:

In KHM 25, "Die 7 Raben", begibt sich die unschuldig-schuldige schwesterliche Anima auf die Suchwanderung nach den in den Glasberg des Totenreiches verwünschten sieben Brüdern. Um die Brüder erlösen zu können, erhält sie vom hilfreichen Morgenstern ein "Hinkelbeinchen" als Schlüssel zum Glasberg. Nach dem etymologischen 'logos' der deutschen Sprache handelt es sich bei diesem "kleinen Knochen" (= Beinchen) um das Schlüsselbein eines (ahd.) "huoni(n)kli(n)" (= nhd. Hinkel), also eines kleinen, folglich jungen (ahd.) "huon" (= nhd. Huhn). Denn das Huhn, besonders das junge Huhn, war dem Zeus-Sohn Hermes heilig, dem Gotte der (Such-)Wanderer und Reisenden, dem Gotte des Findens, dem Gotte des Einganges und des Ausganges. Interessanterweise besitzt der kleine Finger, den sich die Schwester abschneiden muß, um das verlorene Hermes-Schlüsselbein zu ersetzen, eine astrologisch-chiromantische Beziehung zum Planeten Merkur, somit ebenfalls zu dem griechisch-römischen Götterduo Hermes-Merkur.

Ich bezweifle, daß der 1907 in Deutschland geborene Manheim sich - wie weiland Martin Luther - wochenlang Gedanken über die treffende Wiedergabe des doch recht 'merk-würdigen' und mythologisch aussagekräftigen Wortes "Hinkelbeinchen" gemacht hat. Sonst hätte ihm das beim obligatorischen amerikanischen Truthahnessen für die abergläubischen Kinder wichtige Äquivalent "wishbone" (= Wunsch-Knochen) einfallen müssen. Denn vom englischen "bone" zum deutschen "Bein" braucht es keiner großen etymologischen Vorstellungskraft. Und wer noch nie ein altdeutsches beinernes Schachspiel bewundert hat, dem sollte wenigstens die anatomische Wortsequenz "Nasenbein, Jochbein/Wangenbein, Brustbein, Schlüsselbein, Schienbein etc." anhand des eigenen Körpers in den Sinn kommen, vielleicht auch noch das "Beinhaus" auf alten Friedhöfen. Manheim übersetzt jedoch schlicht dreimal "a chicken's leg", 6 also "ein Hühnerbein", das der Morgenstern dem Schwesterchen - so muß man konjizieren - als Wegzehrung zusteckt, wobei er zudem - damit die Portion nicht zu klein ausfällt - das Diminutivum des Deutschen unterschlägt. Dieses "Hühnerbein" als simple sprachliche Fehlleistung aus Unwissenheit des etwa 70-jährigen Manheim abzutun, dürfte den Nagel nicht ganz auf den Kopf treffen. Vielmehr hat der in der amerikanischen Sprache verwurzelte Übersetzer das dieser

6 Vgl. "Grimms' Tales for Young and Old: The Complete Stories". Translated by R. Manheim. Garden City/New York (Doubleday \& Co) 1977, S. 97. 
Sprache für ihre Perzeptionen und Apperzeptionen, damit für ihre Sprachinhalte eigene Analyse- und Bezeichnungssystem naiv auf die perzeptorisch und apperzeptiv anders strukturierte deutsche Text-Vorlage übertragen. Das "Hinkelbein-chen"/Junghuhnnknöchelchen des Hermes, im Deutschen der noch für die Brüder zu leistenden Erlösungs-Aufgabe als Instrumentalis zugeordnet, wird im 'logos' des Amerikanischen eine pragmatisch rückbezogene Referenz auf das Ich-Subjekt der Protagonistin und dessen egozentrische Bedürfnisse, so daß dem Deutschen gegenüber eine Referenz-Umkehrung vorliegt.

Was ich unter dem Terminus "Referenz" verstehe, ist die vom Sprachbenutzer durch seine 'Rede' oder durch seinen 'Text'7 mit Hilfe seines Kognitionssystems auf eine ganz bestimmte, d.h. idiomatische Weise kreierte, weil stilistisch 'ausgedrückte' Beziehung zwischen seinem eigenen Ich und den erst im sprachlichen Ausdruck ureigentlich 'ver-wirklichten' konzeptionellen Gegebenheiten menschlicher Existenz, die als empirisch voretablierte und vordefinierte kognitiv-mentale Wirklichkeiten zu verstehen sind.

Mit diesem Hinweis komme ich zum methodischen Ansatzpunkt und zu den Prämissen meiner Überlegungen. Zum einen gehe ich aus von meiner im November 1994 hier vorgetragenen zweiten Definition der 'Sprache' als Einzelsprache, d.h. als eines absolut 'geschlossenen', dennoch 'offenen' Systems, dessen 'Geschlossenheit' gerade die für mein Thema relevanten Idiome als historisch gewachsene, latent-potente 'subsyntaktische Textsorten' - sprich: Phraseologismen, Redensarten, Redewendungen - permanent speichert ${ }^{8}$ für die virtuelle Reaktivierung durch jeden 'bewußten Stilisten'. Mir war in diesem Kontext bedeutsam, daß diese idiomatisch strukurierte 'Geschlossenheit' der Nationalsprachen auch von einem so experimental-avantgardistischen Lyriker und Essayisten wie dem im September 1996 verstorbenen Helmut Heißenbüttel als "unaufhebbare Abhängigkeit des Subjekts von den Vorgaben der Sprache, aus der nur das deutliche Bewußtsein dieser Abhängigkeit befreien ... (kann)" erfahren und anerkannt wurde. ${ }^{9} \mathrm{Da}$ ich weiterhin von dem Axiom ausgehe, daß jede Nationalsprache ein Perzeptions- und Apperzeptionssystem sui generis darstellt, das sich beim sprachlichen Ausdruck seiner Perzeptions- und Apperzeptionsinhalte ganz eigener, idiomatisch angelegter und festgelegter Referenz-Strukturen bedient, muß man über eine selektiv-repräsentative phänomenologische Bestandsaufnahme idiomatischer Textkomponenten das prototypische Wie und Was, d.h. den "Geist" amerikanischer Idiomatik begreifen können, somit auch die damit verbundenen interferenzialen Kommunikations-Schwierigkeiten deutscher und amerikanischer Sprachbenutzer. Anders ausgedrückt: Es geht mir um eine empirische Applikation und

7 Zur Definition der Termini "Rede" und "Text" vgl. meinen Beitrag: "Sprache, Text und Textsorten: Zur Problematik von Texttypologie". In: Linguistica XXXV, 1: Textsorten. Ljubljana 1995, S. 53-79, hier: S. 64 und $69 f$.

$8 \quad$ Vgl. ebd., S. 57f., S. 68f., S. 70-75.

9 Vgl. Fachdienst Germanistik, 14. Jg., Nr. 11 (Nov. 1996), S. 10. 
Verifizierung der beiden Humboldtschen Sätze: "Die Sprache ist gleichsam die äußerliche Erscheinung des Geistes der Völker; ihre Sprache ist ihr Geist, und ihr Geist ist ihre Sprache... daß er (der Mensch) nichts aus sich hinauszusetzen vermag, das nicht augenblicklich (als idiomatischer Struktur-'logos' seiner Muttersprache nämlich) zu einer auf ihn zurückwirkenden und sein fernes Schaffen bedingenden Masse wird." 10

Um die Crux idiomatischer Textsorten-Übersetzungen und idiomatischer Referenzen in nuce, gewissermaßen prototypisch zu demonstrieren, zitiere ich als Präludium zu meiner anschließenden, etwas konstruierten phänomenologischen Bestandsaufnahme eine zu 100\% authentische amerikanische 'Einfache Form' im Sinne von André Jolles. Ich selbst habe die 'Rede' erstmals Ende 1996 in der Originalfassung des neuen Hollywood-Films "Tin Cup" von Kevin Costner gehört, der sie seinen Bierkumpanen als Rätsel präsentierte. Mein amerikanischer Gewährsmann jedoch einer meiner ehemaligen Studenten und wie Gottfried Benn sowohl Mediziner als auch sprachgewandter Autor - versichert mir, für die amerikanische Sprach-Mentalität sei das kein Rätsel, sondern ein aus den fünfziger Jahren stammender soziologischer Witz. Denn - so wurde mir erst post festum klar - dem nativen Englischsprachigen sollte der "doctor" des 'Witzes' als Utrum bzw. 'nomen commune' bewußt sein, was bei Costners Bierseligen freilich nicht der Fall war:

"A father and a son take a ride together and get into a crash. Each of them is taken to a different hospital for treatment. When the son is taken into the operating room, the doctor takes a look and says, 'I can't operate on the boy, he is my son'."

Ich lehnübersetze zunächst mit direkten idiomatischen Transferenzen, weise im voraus auf die auch hier dominante idiomatische Verwendung von "to take" hin, auf die ich am Schluß nochmals eingehen werde:

- Ein Vater und ein Sohn nehmen zusammen einen Ritt und geraten in einen Zusammenstoß-Krach. Jeder von ihnen wird zu einem unterschiedlichen Hospital für Behandlung genommen. Wenn der Sohn in den Operierraum genommen wird, nimmt der Doktor einen Blick und sagt: "Ich kann an dem Jungen nicht operieren, er ist mein Sohn." -

So übersetzt, bleibt der Text dem Deutschsprachigen ein Rätsel im Sinne der zugehörigen Jolleschen 'Geistesbeschäftigung' eines von Mensch zu Mensch durch das Aufzeigen einer zu lösenden Frage etablierten Wissens-Zwanges. ${ }^{11}$ Als Witz, dessen 'Geistesbeschäftigung' nach Jolles das Komische bzw. die Komik ist, ${ }^{12}$ fungiert der Text für die deutsche Sprach-Mentalität nicht; dafür ist die Proposition zu seriös. Hier scheiden sich die (deutschen und amerikanischen) Geister.

10 Vgl. Wilhelm von Humboldt, Gesammelte Schriften. Hg. von der Königlich-Preußischen Akademie der Wissenschaften. 17 Bde. Berlin 1903-1936. Bd. IV, bes. S. 14.

11 Vgl. A. Jolles, Einfache Formen. 2. Aufl. Darmstadt 1958, S. 126-130.

12 Vgl. ebd., S. 252 - 261. 
Meine zweite Übertragung, mit den 'richtigen' deutschen Idiomatik-Kategorien vorgenommen, annulliert die für amerikanische Sprachbenutzer virtuelle Einfache Form 'Witz', beseitigt auch das dem Deutschsprachigen lexeminhärente Rätselhafte und macht den Text damit banal. Er hat - erstaunlicherweise - seine ursprüngliche Referenz durch eine idiomatisch richtige Reproduktion in einem anderen Sprach- und Denksystem völlig verloren:

- Vater und Sohn machen einen gemeinsamen Ausflug mit ihrem Wagen und verunglücken dabei schwer. Die beiden werden zur ärztlichen Behandlung in verschiedene Krankenhäuser eingeliefert. Als man den Sohn in den Operationssaal fährt, schaut ihn die Ärztin an und sagt: "Ich kann den Jungen nicht operieren, er ist mein Sohn." -

Nach diesem ersten Kurz-Beleg kommunikativer Textsorten-Problematik, der zeigt, wie Witz oder Rätsel eines Sprach-Systems bei der Übertragung in ein anderes zur propositionalen Banalität schrumpfen, verwende ich im folgenden mir indikative Lehnübersetzungen aus der amerikanischen Idiomatik in einer syntaktisch deutschen narrativen Alltagsepisode. Die von mir benutzten Lehnübersetzungen stammen aus 'Reden' und 'Texten' amerikanischer Deutschstudenten und College-Absolventen, amerikanischer Germanistik-Kollegen sowie deutscher Auswanderer. Um die problematische kommunikative Effizienz und propositionale Valenz dieser Lehnübersetzungen für ein monolinguales deutsches Publikum zu belegen und zu testen, lasse ich auf die idiomatisch verfremdete Textversion I als komparativen Kontrast eine idiomatisch korrekte Textversion II folgen, in der die Divergenzen kursiv notiert sind. Vorauszuschicken ist noch, daß meine Belege von im Lexikon des Deutschen durchaus bewanderten Sprachbenutzern stammen. Allen Benutzern gemeinsam war und ist jedoch eine Verankerung in den idiomatischen ReferenzStrukturen der amerikanischen Sprache. Das heißt, die amerikanischen DeutschAspiranten haben das schöpferische 'Übertragen' vom muttersprachlichen in den deutschen 'Bewußtseinsstrom' idiomatischer Sprach-Referenzen noch nicht geleistet, und den Auswanderern ist der ursprüngliche idiomatische 'Bewußtseinsstrom' ihrer deutschen Muttersprache im alltäglichen 'Flusse' praktizierter amerikanischer Idiomatik und Sprach-Referenzen versandet; die deutschen Strukturen ihrer Sprach-Kompetenzen sind durch andersartige amerikanische überlagert und verdrängt worden.

\section{Text I:}

Trotz einer voll-befiederten Erkältung (a full-fledged cold) war Eric allen Totlinien seiner juristischen Abschlußexamen begegnet. (Eric met all deadlines.) Er war niemals spät (He was never late.), obwohl er oft kalt war (though he was often cold). Anschließend feierte er seinen erfolgreichen Studienabschluß ausgiebig, nahm durchaus zahllose Getränke (took quite a lot of drinks). Als der ihm sowieso verhaßte Trainer seiner Korbballmannschaft daraufhin meinte, er solle es leicht nehmen (to take 
it easy) und solle nicht Nüsse über das bestandene Juraexamen sein (should not be nuts about the degree), legte Eric seinen Fuß in den Mund (Eric put his foot into his mouth.) und antwortete ihm, er sei falsch (that he was wrong) und solle sich in Urin auflösen (should piss off). Denn der Trainer hatte ihn für Jahre (for years) wie den niedrigsten Mann am Totempfahl behandet (like the lowest man on the totem pole). Nur hatte Eric nie zuvor die Eingeweide besessen (Eric never had the guts.), ihm ein Stück seines Geistes zu geben (give him a piece of his mind). Nunmehr jedoch trafen die Exkremente den Ventilator (The shit hit the fan.), und der Trainer feuerte ihn (fired him) wütend aus der Mannschaft. Ein Freund, der die Auseinandersetzung überhört hatte (who overheard the dispute), sagte: "Oh, mein! (Oh, my!) Du trägst dein Herz heute wirklich am Ärmel. (You really wear your heart on your sleeve today.) Laß ihn allein! (Leave him alone!)" - Sie gingen zusammen auf die andere Seite des Lokals, und Eric nahm einen Sitz (took a seat) neben einer Studentin in rotem Wollpullover, die er für durchaus etwas Zeit (for quite some time) datieren wollte (wanted to date her). Denn er war ganz genommen mit ihren guten Anblicken. (He was quite taken with her good looks.) Nach der Begrüßung sagte Eric: "Bist du nicht heiß, Anna?" (Aren't you hot, Anna?) Weißt du, ich wollte dich schon immer datieren. (I always wanted to date you.) Kann ich dir an einem dieser Tage (on one of these days) ein Mittagessen kaufen (buy you a lunch)?" - "Meine Mutter meint, es gibt kein freies Mittagessen (There is no free lunch.); aber ich mag dich; ruf' mich morgen (Call me tomorrow.); hier ist meine Nummer (my number)." --- Eric war froh, daß sein Datum (his date) nicht den Abfluß hinuntergegangen war (did not go down the drain). Er dachte: "Was ein glücklicher Hund ich bin! (What a lucky dog I am!)" Und weil er wegen seines Blutalkohols kein Risiko nehmen wollte (He did not want to take a risk.), nahm er einen Ritt in einem Taxi (He took a ride in a taxi.) nach Hause. An einer Kreuzung rannte der Fahrer ein rotes Licht (The driver ran a red light.), aber Eric merkte nichts. In seinem Appartement konnte er gerade noch seinen Sakko an einen Hänger hängen (hang on a hanger), bevor er das Heu traf (hit the hay). Denn er hatte wirklich zu lange auf der Feier ausgehangen (hung out too long at the party). --- Am nächsten Morgen schlief Eric ein (slept in), weil er einen ganzen Überhang hatte (quite a hangover). Halbschlafend (half asleep) dachte er: "Nimm dir deine Zeit! (Take your time!) Ich habe so ein Darmgefühl (a gut-feeling), daß ich heute schlechtes Glück habe (bad luck), wenn ich zu früh aufstehe." Er ließ seine Vorstellungskraft wild laufen (He let his imagination run wild.), dachte an seine Berufsaussichten. Sein Vater hatte ihn an (to) die Parteipeitsche (party whip) der Republikaner in Sacramento empfohlen. Doch er wollte sein Leben vom Riß (from scratch) selbst aufbauen, dabei auch Chancen nehmen (take chances): "Ich bekreuze mein Herz! (I cross my heart!)"Er fühlte nicht wie (He did not feel like...) fürs Amt in einer Partei rennen (running for office in a party), lieber wollte er als Staatsanwalt Verdächtige zur Gerechtigkeit bringen (bring suspects to justice). --- Erst gegen $13 \mathrm{Uhr}$ war er besser (was better), war offenbar auf seinem Wege zur Gesundung (on his way to recovery), obwohl sein Rippenkäfig (his rib cage) noch leicht schmerzte. Als nächste Tür (next door) jemand hämmerte, stand er auf und rief seine stets besorgte Mutter (called his mother). Zuerst hörte sie das Telephon nicht, denn sie nahm - wie jeden 
Mittag - eine Noppe (took a nap) und war gesund im Schlaf (sound asleep). Bevor Eric das Appartement verließ, aß er zwei Heferollen (yeast rolls) mit Butter, blauem Käse (blue cheese) und heißen Hunden mit heißem Senf (hot dogs with hot mustard), bürstete seine Zähne (brushed his teeth) und nahm eine Dusche (took a shower). Nach dem Nehmen einer Dusche (after taking a shower) behandelte er auch noch seinen Athleten-Fuß (his athlete's foot). --- In der Gartenanlage hatte der letzte Donnersturm (thunderstorm) viel Schmutz (dirt) weggewaschen (washed off), deshalb luden die Gärtner gerade eine Ladung Obererde (topsoil) ab. Er nahm einen Ritt (took a ride) mit dem Nr. 10-Bus (number 10-bus) zum nächsten Sportgeschäft. Am Eingang stolperte er, weil er das Zeichen (the sign) "Beobachte deinen Schritt!" (Watch your step!) übersehen hatte. Ein paar Fischenruten (fishing-rods) fielen dabei gegen einen Angestellten, zu dem Eric sagte: "Ich bin besorgt! Entschuldigen Sie mich!" (I am sorry! Excuse me!) Der meinte jedoch nur: "Niemals beachten, mein Herr! (Never mind, Sir!) Kein Schweiß, das wieder zu richten! (No sweat fixing it again!) Wie sind Sie, mein Herr? (How are you, Sir?)" - "Danke Ihnen! Wie sind Sie? (Thank you! How are you?)" - "Kann ich Ihnen helfen, mein Herr?" (Can I help you, Sir?)" --- Eric kaufte eine leichte Fischenrute (fishing-rod) und ließ sich das Senkblei gleich 30 Zentimeter vor dem Fischenhaken (one foot in front of the fishing-hook) an der Fischenleine (fishing-line) befestigen. Leider waren die preiswerten Fischenspulen (fishing reels) schon ausverkauft. Doch Eric bekam einen Regenscheck (rain-check), und der Geschäftsführer überreichte ihm zudem einen Satz Fischenhaken (fishing-hooks) als freies Geschenk (as a free gift). Da Eric erst in zwei Tagen eine Geldüberweisung seiner Eltern erwartete und er seine Schweinchen-Bank (piggie bank) nicht geschlachtet hatte, datierte er seinen Scheck nach (postdated his check). Er freute sich, daß er beim Einkauf nicht hineingenommen worden war (that he had not been taken in), und nahm ein langes Zufußgehen heim. (He took a long walk home.) Dabei nahm Eric sogar einen Umweg (even took a detour) durch den herbstlichen Park, um bei seiner favorisierten Schokoladenküche (at his favorite chocolate kitchen) Schokoladen mit wirklichem Schokoladengeschmack (chocolates with real chocolate flavour) zu kaufen. Die mütterliche Verkäuferin rief ihm noch nach: "Hab' ein gutes Dankengeben, Honig! (Have a Good Thanksgiving, honey!)"

\section{Text II:}

Trotz einer ausgewachsenen Erkältung hatte Eric es geschafft, alle Termine seiner juristischen Abschlußprüfungen einzuhalten. Er kam niemals zu spät, obwohl ihn oft fröstelte. Anschließend feierte er den erfolgreichen Studienabschluß ausgiebig und sprach dabei dem Alkohol reichlich zu. Als der ihm sowieso verhaßte Trainer seiner Korbballmannschaft daraufhin meinte, er solle die Kirche im Dorfe lassen und wegen des bestandenen Jura-Examens nicht durchdrehen, geigte ihm Eric unverblümt die Meinung und trat bei ihm ins Fettnäpfchen, indem er ihm entgegnete, er irre sich und solle für immer und ewig verduften. Denn der Trainer hatte ihn seit Jahren wie den letzten Deppen behandelt, auf dem jeder ungestraft herumhacken konnte. Nur hatte Eric 
nie zuvor den Mumm und die Traute besessen, seinem Ärger Luft zu machen. Nunmehr jedoch kamen ihre heimlichen Spannungen zum Ausbruch, und der Trainer entlie $\beta$ ihn wütend aus der Mannschaft. Ein Freund, der die Auseinandersetzung zufällig mitbekommen hatte, sagte: "Um Gottes willen! Du machst heute aus deinem Herzen wirklich keine Mördergrube. Doch laß ihn in Ruhe!" --- Sie gingen zusammen auf die andere Seite des Lokales, und Eric setzte sich neben eine Studentin in rotem Wollpullover, mit der er sich schon lange hatte verabreden wollen. Denn er war von ihrer Schönheit geradezu besessen. Nach der Begrüßung sagte Eric: "Ist es dir nicht zu warm, Anna? Weißt du, ich wollte mich schon immer einmal mit dir verabreden. Darf ich dich morgen oder übermorgen zum Mittagessen einladen?" - "Meine Mutter meint zwar, man müsse für alles bezahlen; aber ich mag dich; ruf' mich morgen an; hier ist meine Telephonnummer." --- Eric war froh, daß er bei seiner Verabredung keinen Korb bekommen hatte. ${ }^{13}$ Er dachte: "Was bin ich doch für ein Glückspilz!" Und weil er wegen seines Blutalkohols kein Risiko eingehen wollte, fuhr er mit einem Taxi nach Hause. Einmal raste der Fahrer bei Rot über die Kreuzung, aber Eric merkte nichts. In seinem Appartement konnte er seinen Sakko gerade noch auf den Bügel hängen, bevor er ins Bett fiel. Er hatte wirklich zu lange gefeiert. --- Am nächsten Morgen schlief er sich aus, weil er einen Mordskater hatte. Im Halbschlaf dachte er: "Immer mit der Ruhe; $d u$ hast Zeit. Ich habe so eine Ahnung, daß heute alles schiefgeht, wenn ich zu früh aufstehe." Er verlor sich in Phantasien, dachte an seine Berufsaussichten. Sein Vater hatte ihn einem Fraktionsvorsitzenden der Republikanischen Partei in Sacramento empfohlen. Doch er wollte sein Leben von Grund auf selbst aufbauen, dabei auch Risiken eingehen: "Das schwöre ich mir!" Er hatte keine Lust, sich um einen Parteiposten zu bewerben, lieber wollte er als Staatsanwalt Straftäter vor Gericht stellen und bestraft sehen. --- Erst gegen 13 Uhr fühlte er sich besser, war offenbar auf dem Wege der Genesung, obwohl sein Brustkorb noch leicht schmerzte. Als nebenan jemand hämmerte, stand er auf und rief seine stets besorgte Mutter an. Zuerst hörte sie das Telephon nicht, denn sie machte - wie jeden Mittag - ein Nickerchen und war tief eingeschlafen. Bevor er das Appartement verließ, aß er zwei Brötchen mit Butter, Schimmelkäse (Gorgonzola) und heißen Wienern mit scharfem Senf, putzte seine Zähne und duschte. Nach dem Duschen behandelte er auch noch seinen Fußpilz. --- In der Gartenanlage hatte der letzte Gewittergu $\beta$ viel Erde weggespült, deshalb luden Gärtner gerade eine Ladung Muttererde ab. Er fuhr mit dem Zehner-Bus zum nächsten Sportgeschäft. Am Eingang stolperte er, weil er das Warnschild "Vorsicht Stufe!" übersehen hatte. Ein paar Angelruten fielen dabei gegen einen Angestellten, zu dem Eric sagte: "Es tut mir leid! Entschuldigung!" Der meinte jedoch nur: "Das macht gar nichts. Es ist im Nu wieder in Ordnung. Guten Tag, der Herr!" - "Besten Dank. Guten Tag!" - "Womit kann ich Ihnen dienen, mein Herr?" --- Eric kaufte eine leichte Angelrute und ließ sich das Senkblei gleich 30 Zentimeter hinter dem Angelhaken an der Angelschnur befestigen. Leider waren die preiswerten Stationärrollen schon

13 Zur kulturgeschichtlichen Etymologie der Redewendung "einen Korb geben/bekommen" vgl.: M. Wierschin, "Wie es (nicht) im Buche steht". In: Der Schlern $70 / 6$ (1996), S. 364f. 
ausverkauft. Doch Eric bekam einen Gutschein dafür, und der Geschäftsführer überreichte ihm zudem einen Satz Angelhaken als Werbegeschenk. Da Eric erst in zwei Tagen eine Geldüberweisung seiner Eltern erwartete und er sein Sparschwein nicht geschlachtet hatte, datierte er seinen Scheck vor. Er freute sich, daß er beim Einkauf nicht übervorteilt worden war und machte einen langen Spaziergang nach Hause. Dabei machte er sogar noch einen Umweg durch den herbstlichen Park, um bei seiner Lieblings-Konfiserie mit Kakao und Kakaobutter bereitete Pralinen zu kaufen. Die mütterliche Verkäuferin rief ihm noch nach: "Ich wünsche Ihnen ein schönes Erntedankfest, junger Mann!"

Wie ein Vergleich von Text I und Text II zeigt, ruft meine Verwendung lehnübersetzter amerikanischer Idiome in Text I beim deutschsprachigen Rezipienten einen distanzierenden Brechtschen Verfremdungseffekt hervor. Verdeutlichen und belegen diese Idiome doch den oben zitierten unterschiedlichen "Geist", d.h. den reversiven idiomatischen Struktur-'logos' zweier Sprachen. Folglich bricht sich an den in deutsche Kontexte und in eine deutsche Syntaktik eingebetteten amerikanischen Idiom-Inseln der deutsche Apperzeptions-Strom, obwohl diese fremdartigen Pseudo-Idiome sprachlich 'eingedeutscht' worden sind. Vor allem durch ihre fremdartigen Propositions- und Referenz-Valenzen wird für den deutschen Rezipienten eine verzerrte Mimesis der dargestellten Wirklichkeiten geleistet. Konkret heißt das: Obwohl auf Grund einer stetig zunehmenden Flut von Anglizismen und amerikanischen Lehnwörtern im Deutschen manche der in Text I eingesetzten Lehn-Idiome gerade noch verstanden werden können, müssen die meisten rätselhaft, mißverständlich oder unverständlich bleiben.

Gerade noch bzw. vage verständlich sind - auf Grund von kognitiver Analogie oder anhand des Kontextes - folgende selektive Beispiele: "Fischenruten, Fischenspulen, Fischenhaken - Er war niemals spät. Er nahm durchaus zahllose Getränke. Du trägst dein Herz heute wirklich am Ärmel. Er nahm einen Sitz. Es gibt kein freies Mittagessen. Er war besser. Er nahm einen Ritt in einem Taxi. Er nahm eine Dusche. Er nahm ein langes Zufußgehen heim."

Als 'rätselhaft' verstehe ich diejenigen Lehn-Idiome, deren Komponenten für den deutschsprachigen Rezipienten eine inhärente Frage konstruieren, die seine Apperzeption weder anhand der dem Idiom immanenten Auto-Semantik eindeutig beantworten kann noch anhand der aus dem deutschen Sprachsystem transferierten Assoziativ-Semantik. Unter diese Kategorie fallen zum Beispiel: "schlechtes Glück; vom Riß/Gekritzel selbst aufbauen; Rippenkäfig; blauer Käse; Obererde; 30 Zentimeter vor dem Fischenhaken an der Fischenleine befestigen; als freies Geschenk; Schweinchenbank; bei seiner favorisierten Schokoladenküche Schokoladen mit wirklichem Schokoladengeschmack kaufen; gutes Dankengeben." --- Dazu ein paar Glossen: Das Neuhochdeutsche hat die dem Mittelhochdeutschen "lüicke/gelücke/ gluicke" (die etymologische Verwandtschaft von englisch "luck"mit der mittelhochdeutschen Form ist deutlich) und dem amerikanischen "luck"gemeinsame Semantik von 'metaphysische Kraft/Geschick/Zufall mit positiver oder negativer Valenz' seit der 
2. Hälfte des 16. Jahrhunderts zur ausschließlich positiven Bedeutung von "Glück" verengt. Das Amerikanische (und das Englische) dagegen hat die alte Semantik bewahrt; es gibt folglich "bad luck" und "good luck", schlechtes Glück und gutes Glück. - Das amerikanische "scratch" verweist semantisch auf alles, was mit der Hand bzw. Klaue oder mit einem Werkzeug in oder auf einer beliebigen Oberfläche markiert worden ist. In unserem Kontext ist an einen in den imaginativen 'Boden der Gegebenheiten' geritzten Grundriß bzw. Aufriß oder an eine Startlinie zu denken, den bzw. die jemand seiner Zukunft zugrundelegt. - Die deutsche Anatomie-Metapher "Brustkorb" beruht auf funktionalen Analogien und besitzt zugleich eine lokative Referenz: Die vordere obere Hälfte des menschlichen Rumpfes, "Brust" genannt, besitzt die Form eines Korbes, in dem die lebenswichtigen Organe enthalten und geschützt sind. Die amerikanische Metapher "Rippenkäfig" (= rib cage) ist wegen der Polysemie ihrer Komponenten "rib" und "cage" weder anatomisch signifikativ festgelegt noch besitzt sie eine lokative oder logisch-funktionale Referenz. "cage" ist ein ubiquitäres, oft mobiles Behältnis unbestimmter Größe mit mehr oder weniger großen Öffnungen und einer Tür, das Menschen (Gefangene, Aufsichtführende, Magazinverwalter) oder Tiere zumeist ungewollt oder (seltener) gewollt so einschließt, daß sie durch die Öffnungen sichtbar bleiben, aber nicht ins Freie gelangen können, sondern allein durch die Tür. Dem rein deskriptiven Pseudo-Kompositum "Rippenkäfig" (d.h. "Käfig aus Rippen") fehlt zudem, im Sinne von Aristoteles und Quintilian, das entscheidende Kriterium der 'immutatio', nämlich die Analogie der Öffnungen; es ist somit eine rätselhafte Leer-Metapher. - Die gleichen Kriterien gelten - mutatis mutandis - für das Idiom "piggie bank" (= Schweinchenbank); auch dieses bleibt dem Deutschsprachigen eine nicht gerade einleuchtende Leer-Metapher. "Blauer Käse" und "Obererde" demonstrieren ebenfalls die Präferenz des Amerikanischen, monoseme Idiome durch rein empirisch-desriptive OberflächenPhänomene der Signifikate zu etablieren, wobei bei den Farbzuweiseungen "grün" und "blau" recht autonom-willkürlich verfahren wird (s.u.). So ist die berühmte "Green Card" (Aufenthalts- und Arbeitsgenehmigung der USA) nicht grün, sondern blau getönt. - Für den deutschen Perzeptions-'logos' räumlicher Gegebenheiten muß es rätselhaft bleiben, wie ein Senkblei $30 \mathrm{~cm}$ vor dem Angelhaken an der Schnur befestigt werden kann. Denn der Deutschsprachige geht über die referentiell auf das eigene Ich bezogene fragmentarisch-sinnliche Perzeption des Englischsprachigen hinaus und abstrahiert die perzeptorischen räumlichen Gegebenheiten von Angelschnur und Angelhaken zu einem apperzeptiv vorgestellten Gesamtbild, bei dem sich vor dem Angelhaken nichts als Luft befindet, also auch keine Angelschnur, an der sich etwas 'be-festigen' ließe. Im Amerikanischen dagegen, wo das Versalien-"I" nicht nur zum zeitlichen (s.u.: "to postdate a check"), sondern auch zum räumlichen Zentrum des idiomatischen Referenz-Systems gemacht wird, entspricht die idiomatische Sprachlogik den autonomen Konzepten eines 'an-ordnenden' Individuums. - Was dem Deutschsprachigen als Pleonasmus und Paradox erscheinen muß, nämlich das "freie Geschenk", ist auf dem Hintergrund amerikanischer Zivilisation und Ideologie, die sich im Humboldtschen "Geist" ihrer Sprache niedergeschlagen haben, eine propositionale 
Notwendigkeit. Der Amerikaner weiß von früher Jugend an, daß alles seinen Preis hat, $\mathrm{da} ß$ nichts geschenkt wird, daß man für alles zu bezahlen hat. Das Textsorten-Idiom "Es gibt kein freies Mittagessen!" beinhaltet eine Maxime amerikanischer Wirklichkeit und Lebensweise. Auch die Anna des Textes I weiß, daß Eric mit dem "Kaufen" eines Mittagessens ("Can I buy you a lunch?") sich zugleich eine genau festgelegte weibliche Gunst 'erkaufen' will. Ohne erotische Absichten hätte er gefragt (etwa seine Großmutter): "May I invite you for lunch?" Die amerikanischen Spielregeln interpersonaler Beziehungen verwirklichen sich in ihren Textsorten. Wenn also tatsächlich ein anscheinend absichtsfreies Geschenk ohne erwartete Gegenleistung gemacht wird, muß das der Amerikaner durch eine verstärkende, weil semantisch unbedingt erforderliche Tautologie ausdrücken. - Die Polysemie von "kitchen" als 'jede Räumlichkeit, in der durch Erhitzen Eßwaren produziert werden' und von "chocolate" als 'alle Süßigkeiten mit schokoladenartigem Aussehen und Geschmack' sowie die Tatsache, daß es profitabler, daher in den USA üblich ist, Aussehen und Geschmack von schokoladenartigen Süßigkeiten durch braune Speisefarbe und synthetisches Schokoladenaroma zu fabrizieren, erklären Erics Umweg zu seiner LieblingsKonfiserie. - Der lehnübersetzte Wunsch "gutes Dankengeben" - mit einer für das deutsche Singularetantum "Dank" rätselhaften Pluralform - erreichte mich brieflich nicht zum ersten Oktobersonntag, sondern zum 4. Donnerstag im November 1996, dem mit Ferien und großen Familienfesten verbundenen "Thanksgiving Day" der USA, gesetzlicher Feiertag ersten Ranges und zugleich - als "Thanksgiving" - eines der seltenen echten, weil anscheinend apperzeptiv als Ganzheit verstandenen und folglich graphisch realisierten Komposita des Amerikanischen. Daß dem amerikanischen Begriff die deutsche Komponente "Ernte" fehlt, beruht darauf, daß dieser Tag generellen Danksagungen ("thanks") für 'göttliche Güte und Gnaden' ("divine goodness and mercies") gewidmet ist.

'Mißverständlich' bedeutet in meinem Paradigma, daß der deutschsprachige Rezipient anhand von transferierter Assoziativ-Semantik aus der Muttersprache bei seiner Idiom-Apperzeption getäuscht wird. Die von ihm für das betreffende Lehn-Idiom etablierte Semantik ist falsch, weil sie auf fremden, also 'falschen' Signifikationen beruht. Die semantischen Parameter einer Einzelsprache sind nämlich grundsätzlich nicht übertragbar. Bekannt ist das in diesen Kontext gehörige Phänomen der sogenannten 'Falschen Freunde/false friends/faux amis'. Als Beispiele falsch zu verstehender Lehn-Idiome zitiere ich: "Eric war oft kalt. - Er solle es leicht nehmen. Er war falsch. - Ihn wie den niedrigsten Mann am Totempfahl behandeln. - Ihm ein Stück seines Geistes geben. - Der die Auseinandersetzung überhört hatte. - Laß ihn allein! - Bist du nicht heiß, Anna? - Ich wollte dich schon immer datieren. - an einem dieser Tage - Chancen nehmen - Verdächtige zur Gerechtigkeit bringen - Sie war gesund im Schlaf. - heißer Senf - Der Donnersturm hatte Schmutz weggewaschen. Beobachte deinen Schritt! - Wie sind Sie? - Kann ich Ihnen helfen? - Er datierte seinen Scheck nach. 
Eine Reihe dieser Beispiele lassen sich auf die agentive, ichbezogene amerikanische Ausdrucksweise existentiell-transitorischer (= 'Existentia') Erlebnisinhalte durch das Verbum 'sein' zurückführen, die im Deutschen unagentiv zuweisend und zuordnend formuliert werden, weil das Verbum essendi - besonders in seiner finiten Form 'ist' - für den Deutschen dem durativ-finiten Zustand, der 'Essentia' der 'persona', vorbehalten bleibt. Eric ist für den amerikanischen Sprachbenutzer keine kalte Persönlichkeit (He is no cold person.), ihm war nur - wegen seiner Erkältung öfters kalt. Und Anna ist keine brünstige Nymphomanin (She is not on/in heat. She has no hots for Eric.) sie trägt lediglich einen zu warmen Wollpullover. Analog besitzt Erics Trainer keinen falschen, minderwertigen Charakter, er hatte bloß unrecht; weshalb man ihn "in Ruhe", d.h. "mit sich allein" lassen sollte. Und auch die Leer-Frage (s.u.) "Wie sind Sie?/How are you?" erkundigt sich keineswegs nach dem Wesen oder Charakter der oder des Angesprochenen. - Die semantische Crux beim amerikanischen "take it easy" (d.h. 'übertreibe es nicht') basiert auf den irreführenden deutschen AnalogieIdiomen (= 'Falschen Freunden'): "Nimm es nicht so schwer, nimm es leicht! - etwas auf die leichte Schulter/Achsel nehmen - etwas von der leichten Seite nehmen".

Auf grundsätzlichen kognitiven Apperzeptions-Differenzen, die ich jedoch erst am Schluß zusammenfassend interpretiere, beruhen (Die idiomatisch korrekten deutschen Bedeutungen und eventuelle Anmerkungen stehen in Klammern.): "to give him a piece of his mind/ihm ein Stück seines Geistes geben" (= (ihm gegenüber) seinem Ärger Luft machen; "mind" - ags. gemynd, ahd. gimund; lat. ment-/mens- - ist, vergleichbar dem mhd. "muot", komplex polysem und verweist auf die Gesamtpotenzen des menschlichen Verstandes, des Wahrnehmens, Denkens, Begreifens, Erinnerns, Wollens, Empfindens, Fühlens und Verlangens; die jeweilige Bedeutung wird erst signifikativ-kontextuell konkretisiert; das vorstehende amerikanische Idiom ist eindeutig negativ-signifikant, nicht so ambivalent wie das deutsche 'die Meinung sagen') - "overheard/überhört" (= zufällig akustisch mitbekommen; 'Falscher Freund') - "to date/datieren" (= sich auf ein Datum einigen, eine Verabredung mit einem Mitglied des anderen Geschlechts treffen; nicht: das Alter erraten/bestimmen; 'Falscher Freund') - "to take a chance/eine Chance nehmen" (= ein Risiko eingehen, weil - wie bei "luck/g(e)lück(e)" - gegenüber dem Deutschen das Negativ-Zufällige von "chance" dominierend mitverstanden wird; nicht: eine Chance wahrnehmen, beim Schopfe ergreifen; 'Falscher Freund') - "sound asleep/gesund im Schlaf" (= in tiefem Schlafe; denn der Gesunde schläft tief) - "dirt/Schmutz" (= Erde; wie auch "topsoil/Obererde/ Muttererde" belegt, begreift das Amerikanische seine Umwelt rein empirisch-utilitär) "How are you?/Wie sind Sie?" (= Guten Tag, der Herr! Denn auf die pseudopersönliche Frage nach dem eigentlich implizierten essentiellen Sein des Befragten erwartet der Fragende keine Antwort, sondern er erwartet eine identische, gleich unverbindlichrhetorische Leer-Frage, die dem deutschen "Guten Tag, der Herr!" entspricht. Interessant ist die in identischer Funktion, doch weniger essentiell, vielmehr agentiver formulierte britische Variante dieser exemplarischen Gruß-Textsorte: "How do you do?", die in den 40er Jahren vom deutschen Volksmund parodiert beantwortet wurde mit: "Hau du zuerst." In beiden Fällen reagieren Englischsprachige verdutzt bis 
schockiert, wenn man als Deutscher die Grußformel als tatsächliche Frage nach dem Befinden 'mißversteht' und beantwortet.) - "Can I help you?/Kann ich Ihnen helfen?" (= Womit kann ich (Ihnen) dienen? Der Befragte ist nicht hilfsbedürftig, sondern möchte - als Kunde - bedient werden. 'Falscher Freund'.) - "to bring suspects to justice/ Verdächtige zur Gerechtigkeit bringen" (= Straftäter vor Gericht stellen und bestraft sehen; die Bisemie des Idioms wird dadurch kompliziert, daß nach dem auch sonst praktizierten euphemistischen Prinzip des Amerikanischen selbst ein in flagranti ergriffener Straftäter, der dabei einen Polizisten erschießt, bis zu seiner Verurteilung als "suspect"/Verdächtiger bezeichnet wird.) - " to postdate a check/einen Scheck nachdatieren" (= einen Scheck vordatieren; eine gegenüber dem Deutschen radikale Umkehrung der Zeit-Referenz; das Versalien-"I" des Amerikaners versteht sich autonom als zeitliches Zentrum, wie als räumliches Zentrum (s.o.), seines Referenz-Systems) - "like the lowest man on the totem pole/wie den niedrigsten Mann am Totempfahl" (= wie den letzten Deppen, auf dem jeder ungestraft herumhacken kann; angeblich und wahrscheinlich das einzige Idiom des Amerikanischen, das Komponenten aus dem Indianischen des pazifischen Nordwestamerikas enthält; "totem" bedeutet in der Algonkin-Sprache "Verwandtschaft/Schutzgeist"; der Totempfahl zeigt geschnitzte und bemalte Darstellungen des Totemtieres und der diesem Schutzgeist vertikal zugeordneten, also verwandten menschlichen Ahnenreihe; die vertikale Anordnung ergibt sich logisch aus dem benutzten Baum-Symbol und den künstlerischen Darstellungsprinzipien; nach amerikanischer, rein perzeptorischer Simplifikation, den indianischen Totem-Mythos verkennend, trägt jedoch der Unterste dieser Ahnenreihe die Last der über ihm angeordneten Totemsippe; darauf gründet die doppelt negative Semantik des Idioms, in Analogie zum transferierten amerikanischen Hierarchiedenken und seiner "pecking order"/Hackordnung (s.u.: "underdog" und "top dog"); bemerkenswert ist, daß der naturwissenschaftliche deutsche Terminus "Hackordnung", 1922 von Th. Schjelderup-Ebbe geprägt, als soziologische Lehnübersetzung ins Amerikanische übernommen worden ist, weil damit soziale Gegebenheiten der US-Gesellschaft treffend bezeichnet werden konnten.)

Als 'unverständlich' fungieren schließlich diejenigen Lehn-Idiome bzw. LehnTextsorten, bei deren ursprünglicher Genesis eine komplexere, d.h. eine metaphorische 'Stil'-Leistung erbracht wurde. Die ursprünglich über die spezifischen Bild-Potenzen des Amerikanischen verschlüsselte und historisch bewahrte Semantik dieser Idiome läßt sich logischerweise nur dechiffrieren, indem man dem kognitiven 'Geist' amerikanischer Idiomatik nachgeht. Folglich sind einige, die kognitiv-mentalen Strukturen dieser amerikanischen Textsorten-Idiome aufschlüsselnde Kommentare angebracht. In diesem Kontext gehe ich auch noch auf zwei Belege meines Textsorten-Paradigmas ein, die dem Deutschsprachigen per Analogie bzw. Kontext in etwa verständlich werden können.

Die global aus dem amerikanisch dominierten Medienverbund in alle Einzelsprachen hineinschwappenden Lehnwort-Wellen dokumentieren eine irritierende mentale Obsession der neuen 'Lingua franca' mit den anal-genitalen Lexemen und 
Idiomen einer, nach Freud, ${ }^{14}$ infantilen Ontogenesis-Phase. Diese durch non-verbale Kommunikationsformen gleicher Valenz unterstützten Wortschatz-Komponenten sind nicht nur auf die farbigen sozialen Unterschichten der amerikanischen Gesellschaft beschränkt, wo sie eine wahrhaft horrende Frequenz erreichen, sie finden sich auch häufig genug bei allen Mitgliedern der angelsächsischen Academia (daher meine Belege) und - wie etwa Präsident Nixons Watergate-Bänder zeigen - der übrigen amerikanischen 'Oberschicht' des sogenannten "establishment".

Zum lehnübertragenen, im Deutschen bereits als Vulgärlexem etablierten "piss off/sich verpissen" genügt die Anmerkung, daß die Übertragung eine ModusVeränderung gebracht hat. Das amerikanische Verbum wird eigentlich nur als agentiver Imperativ, mit Exklusiv-Referenz auf die 2. Person Singular bzw. Plural, benutzt; es ist niemals - wie das deutsche Äquivalent - auch unagentiv-reflexiv beziehbar auf die 1 . und die 3. Person.

"Aus seinem Herzen eine/keine Mördergrube machen": Diese subsyntaktische Textsorte oder Redewendung basiert auf der metaphorischen lutherischen Lehnschöpfung "Mörder-grube", die im griechischen Original etwa "Räuberhöhle/Höhle der Räuber" lautet, ${ }^{15}$ so daß Luthers Metapher eine eigentliche, überaus bildhafteindringliche 'Stil'-Leistung darstellt. Denn die Räuberhöhle ist zwar ein verborgener, zugleich auch unwirtlicher und gefährlicher Ort, aber sie besitzt nicht die radikale Verborgenheits- und Geheimnis-Semantik, die der Grube eignet, in der Mörder ihre Opfer aus der Welt schaffen. Luther verwandte seine Metapher in Jeremias 7,11 und in Matthäus 21,13. Sie wäre austauschbar gegen das bereits in der Vulgata (Prediger 21,29) als chiastisches Sprichwort variierte Idiom "das Herz auf der Zunge tragen" (= in ore fatuorum cor illorum, et in corde sapientium os illorum = Im Munde (ist) das Herz jener (der) Schwätzer, und im Herzen (ist) der Mund jener (der) Weisen.), das Luther drastisch übertrug als: "Die Narren haben ihr Herz im Maul, aber die Weisen haben ihren Mund im Herzen. "Luthers Übertragung der biblischen Sentenz ging die des Hugo von Trimberg um 1300 voraus: "Tren herze lt im munde, der wsen munt im herzen grunde." Der Redewendung zugrunde liegt die Vorstellung, daß die im Herzen vor- bzw. außersprachlich generierten Empfindungen und Gefühle nicht erst - wie im 'selbstbeherrschten' Normalfall- nach einer Kontrolle und Zensur durch die rationalen Fakultäten des Menschen von der Zunge 'verlautet' werden dürfen, sondern daß die vorsprachlichen Emotional-Schwingungen des Herzens vom Sprachorgan Zunge durch unmittelbaren Herz-Zungen-Kontakt direkt empfangen und impulsiv in Sprache umgesetzt werden. - Die amerikanische Textsorte "to wear one's heart on one's sleeve/sein Herz an seinem Ärmel tragen" verfügt mit ihren der Ich-Hervorhebung dienenden, emphatisch gedoppelten Possessivartikeln über eine pleonastische Semantik-Redundanz. Nach dem 'logos' deutscher Idiomatik würde das Idiom lauten:

14 Vgl. S. Feud, Abriß der Psychoanalyse. Frankfurt/Main und Hamburg 1970, S. $15 \mathrm{ff}$.

$15 \mathrm{Zu}$ diesem und dem Folgenden vgl.: L. Röhrich, Lexikon der sprichwörtlichen Redensarten. Bd. 2. Freiburg/Basel/Wien 1994, S. 704ff. 
"das Herz am Ärmel tragen". Während das Herz im Deutschen wegen seiner Kontrollfunktion über das Seelen-Element Blut vornehmlich als Sitz seelischer Impulse und emotionaler Potenzen begriffen wird, verfügt das Herz im Amerikanischen zudem über ältere rationale Fakultäten, vor allem der Erinnerung, Einsicht und Organisation, d.h. im Herzen des Amerikaners entstehen nach landläufiger US-Meinung seine Überzeugungen und Meinungen. Auch in Europa wissen wir inzwischen, daß der Amerikaner mit seiner Weltanschauung, seinen Überzeugungen und Meinungen (auch mit den banalsten) nicht hinterm Berge hält, sie vielmehr mit Vorliebe emblematisch und als Piktogramm an Autos, Mützen, Jacken, Hemden, Unterhemden usw. zur Schau stellt, bei den genannten Oberbekleidungen nicht nur an Brust und Rücken, sondern auch an den Ärmeln. Das bedeutet, daß der "sein Herz" - als Emblem und Piktogramm - "an seinem Ärmel tragende" extrovertiert-autonome Amerikaner mit seinen Meinungen und Überzeugungen noch offenherziger umgeht als der Deutsche, der sie auf der Zunge trägt oder in keiner Mördergrube verheimlicht.

Die im Idiom "full-fledged cold/voll befiederte Erkältung" enthaltene witzige Metaphorik geht auf die Kolonisationszeit Nordamerikas zurück, als wildes und zahmes Geflügel zu den allgemein genau bekannten, weil hauptsächlichen Proteinlieferanten gehörte. Voll befiedertes Geflügel ist völlig ausgewachsenes Geflügel, mit sämtlichen charakteristischen Federn. Eine ausgewachsene Erkältung zeigt, analog, sämtliche charakteristischen Symptome in vollem Maße. Die 'immutatio' von "full-fledged" ist nicht auf Erkältungen bzw. Krankheiten beschränkt; sie läßt sich auf alle einem Entwicklungsprozeß unterworfenen Konkreta und Abstrakta anwenden.

Eine "deadline/Totlinie" war ursprünglich die innerhalb oder außerhalb eines Zuchthauses in den Boden gefurchte Linie, bei deren Überschreiten der Gefangene von den Wächtern erschossen wurde. Im Metaphorischen der Textsorte bedeutet die "deadline" den endgültigen Termin, dessen zeitliche Überschreitung auf das Vorhaben 'tödlich' wirkt, es unwiderruflich beendet. Das moderne Amerikanische hat damit räurnliche und zeitliche Sprach-Valenzen willkürlich-autonom vertauscht.

Auch die deutsche Idiomatik arbeitet mit einer Nuß-Metaphorik, die 'Nuß' als Kopf-Synonym benutzt. Dabei beruht die 'immutatio' auf den analogen Oberflächenstrukturen von Walnußkern und Menschenhirn (Gehirnwindungen), auf der Analogie von Hohlräumen zwischen Walnußkern und Walnußschale bzw. zwischen Hirnmasse und Schädeldecke sowie der analogen Aufteilung von Walnußkern und Großhirn/Kleinhirn in zwei Hemisphären. Das Deutsche kennt taube/hohle Nüsse und 'Hohlköpfe', dazu das Idiom "eins auf die Nuß (= Kopf) geben"; man kann auch "aus der Nuß sein", d.h. (vor Zorn) kopflos werden, die Beherrschung verlieren. Kinder erhielten - früher - in der Schule gelegentlich vom Lehrer eine 'Kopfnuß'. Obwohl das Amerikanische ebenfalls "nut" als Synonym für "head" verwendet, wird das US-Idiom erst klar, wenn man eine zweite Bedeutung von "nut" in den Wendungen "You are nuts; to go nuts" ("nuts" stets im Plural) berücksichtigt. Was hier zum Tragen kommt, ist die Polysemie von "nut", die u.a. auch 'Schraubenmutter' mit einem Gewinde beinhaltet, welches überdreht, also 'durchgedreht' werden kann. In der Textsorte "to be nuts about 
= über/wegen etwas Nüsse/Schraubenmuttern sein" liegt also eine chiastische Metaphern-Semantik vor, die "nut" als '(Hohl)-Kopf' und "nut" als 'überdrehbare Schraubenmutter' zusammenfaßt. Denn "You are nuts/to go nuts" meint: Du bist bzw. du wirst gerade (to go) - wie eine Schraubenmutter - in deinem Kopfe ("in your nut") überdreht, also 'durchgedreht'. Beim 'Durchdrehen' kann die "nut/Nuß/Schraubenmutter" auch ihre Verbindung zum Rumpf verlieren; man reagiert daraufhin 'kopflos' und hat 'eine Schraube bzw. ein paar Schrauben locker'.

Für das amerikanische Idiom "to put one's foot into one's mouth/seinen Fuß in seinen Mund legen" gelten die gleichen strukturellen Beobachtungen wie für "to wear one's heart on one's sleeve". Die Doppelwertigkeit des Idioms ("unverblümt die Meinung sagen/geigen und ins Fettnäpfchen treten") basiert auf einer doppelten Signifikation. Einerseits ist es infantil und unkontrolliert, zudem nur im noch irrational definierten frühen Kindesalter physisch möglich, den Fuß in den Mund zu legen, es sei denn, man verfügt über die Fakultäten des indischen Gottes Vishnu. ${ }^{16}$ Daher befindet sich derjenige temporär im Zustande einer rational unkontrollierten Infantilität, der indikativ-symbolisch "seinen Fuß in den Mund steckt", indem er naiv-unverblümt seine Meinung sagt bzw. 'geigt', ohne auf die Konsequenzen zu achten. Indem er das tut, tut er andererseits und zugleich etwas von den 'elterlichen' bzw. gesellschaftlichen Autoritäten Verbotenes; d.h. "er tritt" - mit seiner unverblümten Äußerung - "ins Fettnäpfchen". Denn ein der Infantilität und Naivität des Kindesalters entwachsener Erwachsener "legt seinen Fuß nicht mehr in den Mund", er tut vielmehr das Normativ-Rationale.

Das amerikanische Verbum "to hang" ist überaus polysem und findet sich in einer ganzen Anzahl idiomatischer Wendungen. "to hang out (at a party)/auf einer Feier/Fête aushängen" hat nichts mit der deutschen Grundbedeutung von 'hängen' zu tun, nämlich 'von einem Festpunkt aus schweben oder festgehalten werden bzw. sich in einer genügend fixierten Schräglage/Hanglage befinden', was wiederum - in allen drei Teilaspekten - unagentiv ist. Vielmehr bezieht sich das "hang out" auf die berufliche Praxis der ruhelosen amerikanischen Pionierzeit, seine - mit der Wohnung stets identischen - Geschäftsräume, d.h. seinen eigentlichen Aufenthaltsort, durch ein agentives 'Aushängen' eines Namens- oder Firmenschildes zu bezeichnen. In diesem Sinne bedeutet das noch immer agentive und ursprünglich - als "to hang out my sign/my shingle" - transitive Idiom, nunmehr als elliptisches "to hang out", nichts weiter als '(meist temporär) an einem bestimmten Ort sein'. Was dann als "over/über", als 'Überbleibsel' also, von dem "hang out", dem temporären 'Sein an einem bestimmten Ort' am folgenden Tage noch übrig ist (nämlich ein 'Katarrh' = 'Kater'), wird prosaisch zum "hangover" = 'Übrigseienden', wird $\mathrm{zu}$ dem, was dem nunmehrigen Aufenthaltsort als Überbleibsel 'uiber-hängt'.

16 Merkwürdigerweise zeigen mythische Darstellungen, wie Vishnu kontemplativ auf dem Lotus liegt, mit dem linken Fuß bzw. dem linken großen Zeh im Munde. Vgl.: W. Bauer u.a., Lexikon der Symbole. 13. Aufl. Wiesbaden 1992, S. 60 und 71. 
Ebenfalls aus der Pionierzeit des Wilden Westens stammt das Idiom "to hit the hay/das Heu treffen, schlagen". Die Annahme, es habe sich dabei um eine mit Heu ausgestopfte Matratze oder um eine mit Heu gefüllte Bettstatt gehandelt, auf die der Cowboy mit Elan fiel, wäre freilich falsch. Vielmehr schaffte es der Spätheimkehrer eben nicht mehr vom "saloon" bis zum heimischen "hang out", sondern er 'traf' unterwegs den erstbesten Heuhaufen, um dort sein 'Überbleibsel-hangover' loszuwerden.

Amerika ist das Land alluvialer Regengüsse, besonders während der Regenzeit in den Südstaaten. Dabei fiel früher öfter einmal der Zulieferverkehr der Geschäfte ins Wasser, so daß den Kunden auch heute noch für vorübergehend ausverkaufte Sonderangebote ein apologetischer Gutschein als kausative Leer-Metapher "rain-check/ Regenscheck" übergeben wird.

$\mathrm{Zu}$ den willkürlich 'angeordneten', empirisch-funktionalen Leer-Metaphern des Amerikanischen gehört auch der "athlete's foot/AthletenfuB" als Bezeichnung eines allgemein bekannten, weil von allen amerikanischen Sportlern in Duschräumen und Kunststoffschuhen kultivierten Fußpilzes, für dessen Behandlung es überall zahlreiche, meist unwirksame Medikamente zu kaufen gibt.

Die metaphorische 'immutatio' der Textsorte "party whip/Parteipeitsche", wodurch dem seine Abgeordneten mit eiserner Disziplin kontrollierenden Fraktionsvorsitzenden eine für Europa undenkbare Form der Autorität zugesprochen wird, illustriert die im Grunde sub facie weniger demokratischen als hierarchischen Strukturen der amerikanischen Wirtschaft und Politik.

Auch im deutschen Idiom "das Kreuz über etwas schlagen" steckt eine magisch-segnende Valenz, die dem Unheil gegenüber sowohl präventiv als auch - nach abgewendetem Unheil - gratial sein kann. Wenn der Amerikaner "sein Herz bekreuzt/crosses his heart", dann handelt es sich dabei wiederum um eine durch den Possessivartikel und die Semantik des Idioms etablierte Ich-Referenz. Denn während das "Über" der deutschen Textsorte eine abstrahierende Distanz zum Gesegneten beinhaltet, der Segen selbst vom Ich aus gegen ein virtuelles oder gegen die Nachwirkungen eines gerade erst überstandenen Unheils gerichtet ist, bezieht sich der idiomatische Kreuz-Segen des Amerikaners agentiv und ichbezogen auf sein Herz ('Er bekreuzt sein Herz.'), d.h. auf das sowohl rationale (s.o.: "das Herz am Ärmel tragen") als auch emotionale Zentrum seines Ich. Der Segen ist also nicht gegen ein von außen kommendes Unheil gerichtet, sondern gegen eine potentiell von innen, aus dem eigenen Herzens-Ich kommende Schwäche, einen einmal rational gefaßten Entschluß emotional nicht durchhalten zu können.

Wie kommt die "Noppe" zum "Nickerchen/nap"? Das amerikanisch-englische "nap" - entstanden aus mittelenglisch "noppe", altenglisch "(wull)hnoppa" - ist mit dem deutschen "Noppe" etymologisch-semantisch verbunden. Denn beide Lexeme bedeuteten und bedeuten: 'eine in Garn oder Gewebe als Knoten, Flocke oder Schlinge hervortretende weiche Oberflächenstruktur'. Folglich ist ein mit zahlreichen Noppen versehenes weiches Gewebe dem Amerikaner dafür prädestiniert, als Bettungsunter- 
lage zu dienen für ein Schläfchen während des Tages. Und zwar bezeichnet der schläfrige Amerikaner besagtes Gewebe doppelt metonymisch, d.h. impliziert ist eine zweimalige 'pars-pro-toto'-Reduktion, die das Noppen-Gewebe erstens reduziert zum Plural "Noppen/naps" und zweitens reduziert zum Singular "Noppe/nap". Damit nicht genug. Die "Noppe/nap" des Amerikaners wird weiterhin zum agentiv 'genommenen' Reduktions-Symbol, zum referentiellen Analogon für den 'leichten Mittagsschlaf'. Der Amerikaner "takes a nap", 'er nimmt eine Noppe', während der Deutsche deskriptiv-metaphorisch 'ein Nickerchen macht', das ihm - wie die Diminutivform anzeigt - lieb und wert ist.

Mit dem Hinweis auf die Funktion des Verbums "to take" in dieser Redewendung wird eine auffällige Eigenart zahlreicher amerikanischer Textsorten-Idiome berührt, nämlich eine bevorzugte Verwendung des agentiven "to take", was im Deutschen gelegentlich einem 'machen' entspricht. Ich zitiere ein paar selektive Beispiele, verweise dabei außerdem auf meinen obigen Rätsel-Text und auf Text I: "to take a ride to the mountains"/einen Ausflug in die Berge machen; "to take it easy"/es sich bequem machen; "Don't take it seriously!"/Mache dir nichts daraus!; "to take pains"/sich große Mühe machen/geben; "to take stock"/Inventur machen; "to take a picture"/ein Photo machen; "to take the blame for"/verantwortlich gemacht werden für; "He was taken with her good looks."/Thr gutes Aussehen/ihre Schönheit machte ihn verliebt. - Das Amerikanische verfügt über eine überraschend große Frequenz von Textsorten mit "to take". Wie der vorstehende Rätsel-Text zeigt, kann man eigentlich alles 'nehmen'. Das läßt sich so interpretieren, daß das Ich des Amerikaners es offenbar bevorzugt, zu nehmen oder genommen $\mathrm{zu}$ werden. Mein amerikanischer Gewährsmann kommentierte, obwohl die deutsche Wiedergabe von "to take" durch 'machen' in der Minderheit ist: "Germans make, Amerikans take - the ultimate consumers." (Deutsche machen, Amerikaner nehmen - (als) die perfekten Konsumenten.) Für mich zeigt sich in den amerikanischen "to take"-Textsorten eine starke possessive Subjektivation, der im Deutschen eine transitive Objektivation gegenübersteht.

Eine Subjektivation sehe ich auch in der Referenz-Umkehrung (wie bei Manheims "chicken's leg") des amerikanischen Idioms "to sleep in/einschlafen" gegenüber dem deutschen "sich ausschlafen". Das amerikanische Ich schläft agentiv in den vor ihm liegenden Zeitabschnitt des Tages hinein, ähnlich wie im deutschen Phraseologismus "in den Tag hineinschlafen". Allerdings ist diese deutsche Wendung akausal determiniert, während beim amerikanischen Idiom ein Kausalzusammenhang impliziert ist, in unserem Fall der des "hangover/Kater". Das deutsche "Ich schlafe mich aus." ist gegenüber dem agentiven "I sleep in." unagentiv. Es ist nicht - wie im Amerikanischen - das Ich, das hier 'aus-schläft', sondern das Patienssubjekt "mich", das wiederum determiniert ist durch den dahinterstehenden Kausalzusammenhang einer - wie immer begründeten - Müdigkeit. Mit anderen Worten: Der Deutsche schläft seine im "sich" des Idioms denotierte 'persona' aus einer sprachlich als abstraktes Konzept vorgestellten Müdigkeit hinaus. 
$\mathrm{Zu}$ einer semantisch ähnlichen Differenzierung führt die idiomatische Antithetik von "lucky dog/glücklicher Hund" und "Glückspilz". Über die differenziertere amerikanische Semantik von "luck" als "good luck" und "bad luck" habe ich bereits oben gesprochen. Gemeinsam ist dem Amerikanischen und dem Deutschen, daß sowohl "dog/Hund" als auch "Pilz" metaphorische Identifikationen des menschlichen Ich als symbolträchtige Allegorien sind. Doch fehlt dem amerikanischen Idiom wiederum die eigentlich konstitutive 'immutatio', das referentielle Analogon also. Es ist damit eine dem 'logos' der Sprache-an-Sich widersprechende willkürliche Leer-Allegorie. Denn weder ist das "luck/Glück" ein Hund bzw. hündisch noch ist ein "dog/Hund" glücklich bzw. eine Glücksallegorie. Das belegen die amerikanischen und deutschen Textsorten: "to go to the dogs" (vor die Hunde gehen, auf den Hund kommen) - "to lead a dog's life" (wie ein Hund leben/ein Hundeleben führen). Zur negativen Hunde-Symbolik gehören ferner: "dog-eat-dog" (Hund frißt Hund; jeder ist des anderen Wolf; außerdem: Zwei Hunde an einem Bein kommen selten überein.); "a dog in the manger" (ein Hund in der (Heu-)Krippe = etwas (das 'Heu') aus Neid keinem anderen gönnen, obwohl man selbst damit nichts anfangen kann); "to put on the dog" (den Hund anziehen = jemanden betrügen und täuschen; den Wolf im Schafspelz spielen); "a dogsbody" (ein 'Hundekörper' = jemand der ein Aschenputtel-Dasein führt, alles tun muß, was den anderen zuwider ist); jemandem einen Hund antun = jemanden zu Tode beleidigen, entehren, indem er nach mittelalterlicher Rechtspraxis einen Hund öffentlich herumtragen mußte bzw. zusammen mit einem Hund gehängt wurde; außerdem ist an die Hunde-Schimpfwörter vieler Sprachen zu denken, deutsch etwa: Schweinehund, blöder Hund, falscher Hund, hundsgemeiner Kerl, Hundsfott. Der "glückliche Hund" des Amerikanischen ist demnach das agentive Ich in der Meute der übrigen 'Hunde' - man denke dabei an den "underdog/Unterhund" (den Benachteiligten, Unterlegenen)sowie den "top dog/Spitzenhund" (den Leithund, der alle anderen Hunde kontrolliert und beherrscht) der US-Soziologie - dem ein akzidentiell-transitorischer 'Zu-Fall' (im Sinne des Boethius oder des Angelus Silesius, als 'Eutychia') eine temporäre 'hündische', und das kann nur bedeuten, eine materiellsinnliche 'Be-vor-zugung' zugespielt hat, einen symbolischen 'Fleischknochen' also, der hier als positives "good luck" begriffen wird. Das ist eine durchaus pragmatischempirische, zugleich indikative Allegorisierung des amerikanischen Ich. Das deutsche Textsorten-Idiom "Glückspilz" dagegen wird zum metaphorisch-allegorischen Symbol, indem der Begriff des 'Glücks' - und zwar als zuständliche 'Eudaimonia' - aus dem sprachlichen Sinnbezirk der Philosophie auf den botanischen Begriff 'Pilz' aus dem sprachlichen Sinnbezirk der Biologie übertragen wird. Das referentiell exakte und potente metaphorische Symbol "Glückspilz" ist somit zugleich Allegorie einer positiv-permanenten, kreativ-geistigen Potenz, die sich im Verbum "glücken" manifestiert. Denn der Allegorie-'persona' "Glückspilz" 'glückt' alles, worum sie sich aktiv-kreativ bemüht; der "glückliche Hund" dagegen muß passiv auf den nächsten 'Zu-Fall' der Fortuna des Boethius warten. Das bedeutet, daß sich das deutschsprachige Ich über seine Allegorese "Glückspilz" mit einer geistigen Abstraktion identifiziert, in 
der dem Philosophem 'Eudaimonia' das magisch-volkskundliche Seelen- und 'ordo'Symbol 'Pilz' zugeordnet ist.

Die ausschließlich als Pluraletantum "guts" benutzte Komponente des amerikanischen Idioms "to have the guts/die Eingeweide haben" ist ein ursprünglich nur in der Vulgärsprache der englischen Gosse beheimatetes Lexem, dessen Grundbedeutung 'Bauch, Unterleib, Eingeweide' im gleichen Sprachmilieu zunächst bedeutungsverengt wurde zu: 'alle wichtigen Teile, im besonderen Herz, Leber, Magen der Eingeweide', schließlich als anthropozentrische Metapher benutzt wurde für die diesen Organen zugeschriebenen Empfindungen 'Mut, Tapferkeit, Charakterstärke, Widerstandskraft, Energie'. Jemand, der "lily-livered" war, eine 'Lilien-Leber besaß', verfügte über keine - so die phraseologsiche Umschreibung der Gebildeten für "guts" "intestinal fortitude/Seelenstärke der Eingeweide". Während der Pionierzeit der Neuen Welt kam als idomatisch-semantische Anreicherung hinzu, daß man für ein gesundes Fortkommen und Überleben im amerikanischen Westen tatsächlich ein unempfindliches und widerstandsfähiges Verdauungssystem ("guts") brauchte sowie eine durch die wesentlichsten Organ-Komponenten dieser "guts" etablierte ausdauernd-kräftige Konstitution. Dieser Aspekt scheint mir jedenfalls die Popularität des Idioms im Vokabular der amerikanischen Westküsten-Intelligenzija zu erklären. Auf analoge Semantik-Strukturen verweisen deutsche Idiome, die sämtlich auf medizinischen Anschauungen der Antike und des Mittelalters zurückgehen, nämlich: "frei von der Leber weg sprechen; etwas frißt ihm an der Leber; ihm ist eine Laus über die Leber gelaufen; er hat nicht das Herz dazu; sich zu Herzen nehmen; etwas auf dem Herzen haben; sein Herz ist ihm in die Hose/Stiefel gerutscht; er kann das nicht verdauen; es liegt ihm schwer im Magen; dazu gehört ein guter Magen". Zu welchem Extrem sich die amerikanische ichbezogene Symbol-Metaphorik versteigen kann, zeigt die Wendung "to hate someone's guts" (jemandes Eingeweide hassen) in der Bedeutung: 'das ganze Wesen des betreffenden Menschen verabscheuen'. - In diesem Kontext sei auch nochmals auf die schon oben berührte semasiologische Ichbezogenheit amerikanischer Höflichkeits-Textsorten hingewiesen und einiges ergänzt. Wo der Deutsche unagentiv und indirekt, unter Zurücknahme seiner 'persona' sagt: "Es tut mir leid! Entschuldigen Sie bitte (was ich eben getan habe)! Ich freue mich schon jetzt auf unser Wiedersehen!", setzt der Amerikaner: "Ich bin besorgt! (I am sorry!) Entschuldigen Sie mich! (Excuse/Pardon me!) - Ich bin vorwärtssehend auf (das) Dich-Sehen! (I am looking forward to seeing you!)"

Ich habe bereits in Parenthesis auf die starke Frequenz anal-genitaler Textsorten im Amerikanischen hingewiesen und auf die relative Häufigkeit von Leer-Metaphern ohne 'immutatio', ohne referentielles Analogon, bei denen sich das autoritäre Ich über den 'logos' der Sprache-an-Sich hinwegsetzt, indem es willkürlich 'ver-fügt' und 'an-ordnet'. Um idiomatisch-bildhaft auszudrücken, daß die progressiv aufgestauten heimlichen Spannungen zwischen zwei Individuen plötzlich in den vor allem verbalen Reaktionen des einen zum Ausbruch kommen können, hat das Amerikanische jedoch merkwürdigerweise eine syntaktische Vulgär-Metapher kreiert, die mit einer 
ausnahmsweise präzisen agentiv-anthropozentrischen Zweifach-'immutatio' arbeitet, nämlich das Idiom "the shit hits the fan/die Exkremente treffen den Ventilator". Etymologsich gehören althochdeutsch "sczan" und altenglich "sctan" zur gleichen indogermanischen Wurzel "*skei-" mit der Bedeutung 'scheiden, absondern'; eine gleiche Begriffsbildung gilt für das lateinische "excernere, excrevi, excretum" = 'ausscheiden, aussondern' und die Substantivierung "excrementum" = 'Ausscheidung'. 'Aus-scheidungen' ereignen sich kausal. Sie beruhen auf einem agentiv vom Ausscheidenden erzeugten Druck bzw. einer kausativen Spannung. Der plötzliche verbale Ausbruch einer seit langem akkumulierten mentalen Spannung zwischen zwei Opponenten beruht auf einem durch ständige verbale Reibereien erzeugten inneren Druck, der akustisch durch Atemstrom und Artikulationsdruck freigesetzt, 'ab-gesondert' wird. Hierin realisiert sich das erste referentielle Analogon, die erste 'immutatio' der amerikanischen Metapher. Die zweite objektiviert sich darin, daß sowohl der erregt-'durchgedrehte', seinen Ärger artikulierende Mensch als auch der 'durchdrehende' Ventilator des Idioms das von ihnen jeweils mit Hilfe eines Luftstromes Ausgedrückte bzw. Verteilte unstrukturiert 'ab-sondert'. In beiden Fällen entstehen akustische Turbulenzen. Die dagegen unagentiv zuordnende und mit anderen Referenz-Strukturen arbeitende deutsche Idiomatik verwendet für den gleichen Sachverhalt folgende Textsorten: "Mir platzt der Kragen. - Das Maß ist voll. - Mir reißt der Geduldsfaden. - Das schlägt dem Faß den Boden aus, bringt es zum Überlaufen. Mit der Geduld am Ende sein."

Gibt es für die von mir vorgeführten und diskutierten idiomatischen Phänomene des amerikanischen Englisch eine Exegesis? Ich offeriere abschließend folgende, empirisch begründete und oben belegte, Thesis:

Das Ich, als Humboldtsche 'energeia' des personalen Verhaltens, dominiert beim amerikanischen Englischsprachigen als essentiell-geistiger Zustand einer betonten Ichbewußtheit die sprachliche Hervorbringung. Dem amerikanischen Englischsprachigen ist sein Majuskel-"I" - ganz im Sinne des deutschen Idealismus, besonders im Sinne von Johann Gottlieb Fichte - die zentrale Instanz autoritärer sprachlicher Erfassung und Benennung, autoritärer sprachlicher 'Ver-Fügung' und 'An-Ordnung', von materiellen und immateriellen Gegebenheiten der menschlichen Existenz, wobei sich dieses "I" oft mit einer extrovertiert-denotativen sprachlichen Perzeption begnügt. Das heißt, erst durch die mittels der Sprache vollzogene Referenz vom autoritärgenerativen Ich her erhalten diese Dinge oder Gegebenheiten oder Wirklichkeiten einen dem Ich spezifischen und in ihm agentiv verankerten und verwirklichten Sinn. Anders ausgedrückt: Für den amerikanischen Englischsprachigen ist sein Ich cartesianisch definiert als der solipsistisch-unabdingbare, stets agentiv-generative Ausgangspunkt aller als Daseinsdeutung und Daseinsbewältigung zu verwirklichenden SprachReferenzen. Für den Deutschsprachigen dagegen sind Wirklichkeiten, Gegebenheiten und Dinge menschlicher Existenz der 'persona' des Individuums ${ }^{17}$ durch 
introvertiert-kognitive Abstraktionsmodelle gegenübergestellte Bezugsgrößen, d.h. sie sind Ausgangspunkte, Koordinaten und Ich-Determinanten eines oft unagentiven sprachlichen Apperzeptions-, Ordnungs- und Zuordnungsgefüges, in dem die Vektoren der sprachlichen Bezugsreferenzen dem Amerikanischen gegeüber geradezu reversiv verlaufen oder zumindest verlaufen können.

Die Textsorten-Idiomatik jeder Nationalsprache ist ein in ihrem 'offenen System' ständig expandierendes historisches Kontinuum, wenn sie nicht veröden soll. Diese kontinuierliche idiomatische Expansion und Regeneration, die auch in der interkulturellen Kommunikation stattfindet, muß freilich nach den historisch gewachsenen und etablierten, ganz eigenen inneren Parametern jeder Nationalsprache, d.h. in dem spezifischen 'geschlossenen System' ihrer Textsorten-Idiomatik geschehen, wie mein Idiomatik-Vergleich gezeigt hat. Eine perzeptorisch-geistig nicht assimilierte und idiomatisch nicht transformierte Transferenz aus einem fremden, vor allem referentiell anders gewachsenen und strukturierten Sprachsystem bedeutet eine Bedrohung und Zerstörung der eigensprachlichen kognitiven Kohärenzen. Wie das in der gegenwärtigen Praxis des Globalkommerzes aussieht, belegt ein eklatantes Text-Beispiel der deutschen Modemacherin Jil Sanders, in dem sich eine forcierte sprachliche Kolonisation durch amerikanisches Textsorten-Englisch so demonstriert, daß amerikanische Lehnwörter als unbegriffene Pseudo-'Metaphern' dümmlich in einer deutschen Syntax posieren und eine kommunikative Null-Leistung vollbringen ${ }^{18}$ : "Ich habe vielleicht etwas Weltverbesserndes. Mein Leben ist eine giving-story. Ich habe verstanden, daß man contemporary sein muß, das future-Denken haben muß. Meine Idee war, die hand-tailored Geschichte mit neuen Technologien zu verbinden. Und für den Erfolg war mein coordinated concept entscheidend, die Idee, daß man viele Teile einer collection miteinander combinen kann. Aber die audience hat das alles von Anfang an auch supported. Der problembewußte Mensch von heute kann diese Sachen, diese refined Qualitäten mit spirit eben auch appreciaten. Allerdings geht unser voice auch auf bestimmte Zielgruppen. Wer Ladyisches will, searcht nicht bei Jil Sanders. Man muß Sinn haben für das effortless, das magic meines Stils." 19

\section{Zusammenfassung:}

Mein Beitrag beruht auf dem empirischen Axiom, daß sich sowohl das amerikanische Englisch als auch das Deutsche bei der sprachlichen Verwirklichung ihrer Textsorten-Idiome eines Perzeptions- und Apperzeptionssystems sui generis sowie spezifisch-eigenartiger Referenz-Strukturen bedienen, die in der Idiomatik

rationalis individua substantia." ('persona' ist die individuelle Substanz einer vernunftbegabten Natur.)

18 Wie lächerlich diese angloamerikanische Kraftmeierei auf native Sprachbenutzer wirkt, hat der amerikanische Fernsehstar David Letterman deutlich verbalisiert in: "Zeit"-magazin Nr. 10 vom 28.2.1997, S. 12.

19 Zitiert ist der Text nach: "Der Spiegel" 14 (1996), S. 270. 
beider Sprachen angelegt und fixiert sind. Folglich ergeben sich, akzentuiert im idiomatischen Textsorten-Bereich, semasiologische Kommunikationsprobleme, die ich anhand eines mit authentischen amerikanischen Lehnübersetzungen deutscher Idiome ausgestatteten narrativen Paradigmas exemplarisch-empirisch belege und interpretiere. Ziel meiner Untersuchung war, das Wie und Warum amerikanisch-deutscher idiomatischer Sprach-Divergenzen zu beleuchten und zu beantworten. Mein schließliches Resultat - verkürzt referiert - lautet: Die Ich-'energeia' des amerikanischen Englischsprachigen ist, im Sinne von Descartes und Fichte, die zentrale Instanz einer ich-referentiellen, agentiv-generativen, solipsistisch-autoritären sprachlichen Erfassung und 'An-Ordnung' bzw. 'Ver-Fügung' menschlichen Seins, während sich die nach Boethius definierte deutsche 'persona' für ihr unagentives sprachliches Apperzeptions-, Ordnungs- und Zuordnungsgefüge kognitiver Abstraktionsmodelle bedient.

\section{Povzetek}

"HINKELBEINCHEN" IN "LITTLE CHICKEN'S LEG": NEMŠKI IN ANGLEŠKI FRAZEOLOGEMI KOT PROBLEMATIKA BESEDILOZVRSTNEGA SPORAZUMEVANJA

Moj članek sloni na empiričnem aksiomu, da se tako ameriška angleščina kot tudi nemščina pri jezikovnem uresničenju svojih besedilnovrstnih idiomov poslužujeta posebnega percepcijskega in aperzepcijskega sistema kot tudi specifično-nenavadnih referenčnih struktur, ki temeljijo v idiomatiki obeh jezikov. Iz tega sledijo, predvsem v idiomatičnem besedilnovrstnem področju, semaziološki komunikacijski problemi, ki jih dokazujem in interpretiram eksemplarično in emprično s pomočjo narativne paradigme, opremljene $z$ avtentičnim ameriškim prevodnim kalkom nemških frazemov. Cilj moje raziskave je bil pojasniti vprašanje, kako in zakaj prihaja do ameriško-nemških frazeoloških jezikovnih divergenc. Končni rezultat - na kratko - je: jaz-'energeia' ameriških angleško govorečih je, v smislu Descartesa in Fichteja, centralna instanca na "jaz" nanasajočega se, agentivnogenerativnega, solisistično-avtoritarnega jezikovnega pojmovanja in razporeditve oz. razpolaganja človeške biti, medtem ko se po Beothiusu opredeljena nemška 'persona' za svoje neagentivno jezikovno apercepcijsko, ureditveno in določevalno zgradbo poslužuje abstrakcijskih modelov. 